Chapter 27

\title{
The Role of Ethics in Public Health Clinical Research
}

\author{
C. N. Fokunang, E. A. Tembe-Fokunang, P. Awah, \\ M. Djuidje Ngounoue, P. C. Chi, J. Ateudjieu, \\ R. Langsi, Lazare Kaptue and O. M. T. Abena \\ Additional information is available at the end of the chapter
}

http://dx.doi.org/10.5772/52478

\section{Introduction}

The public health ethics look at the moral basis of the health of human as a guiding support put in place to maximize welfare, and therefore health as a component of welfare $[1,2]$. This view frames the core moral challenge of public health as balancing individual liberties with the advancement of good health outcomes.

An alternative view of public health ethics characterizes the fundamental problematic of public health ethics differently: what lies at the moral foundation of public health is social justice [2]. While balancing individuals' liberties with promoting social goods is one area of concern, it is embedded within a broader commitment to secure a sufficient level of health for all and to narrow unjust inequalities [2,3]. Another important area of concern is the balancing of this commitment with the injunction to maximize good aggregate or collective health outcomes. Public health ethics has therefore a strong moral connection to broader questions of social justice, poverty, and systematic disadvantage [3,4].

\subsection{Historical ethical perspective}

Although there have been some manifested concerns about the vulnerability of human subjects implicated in clinical research for over a century, it was the scandals and tragedies of the Nazi doctors during the second World War that gave birth to the discipline of bioethics [4, 5]. Other recent concerns in bioethics are attempting to extend ethical debate beyond the one-to-one physician-patient relationship, to enter the domain of public health where focused is geared towards the health of the entire populations. In the Africa setting, these extended concerns are being driven in part by the persisting iniquities and disparities in the health status of the low income resource countries and the rich countries, the differences in access to health services, 
the differences in the effort put into solving health problems, whereby the larger health burdens of the South receive scarce research attention, and the fewer problems of the North receive most of the attention in what has been termed the 10/90 gap [6, 35]. More attempts made to redress these inequalities have led to greater research investment and North-South research collaboration with the aim of solving the major health problems affecting the population in the poor countries of the South [7, 35].

\subsection{The Ethical fundamental principles}

Four fundamental principles of ethics have been universally recognized namely; autonomy, beneficence, non-maleficence and justice. These principles universally deals with the respect for all other humans as moral equals, making sure that all our actions are intended to achieve results with less harm, and treating others with fairness and equity $[8,48]$.

\subsubsection{Beneficence and non maleficence}

The principle of beneficence and non-maleficence are best considered together as they are like mirror images of each other. Literally beneficence means doing good and non-maleficence means avoiding evil or harm $[9,38,42]$.

\subsubsection{The harm principle}

It is likely that no classic philosophical work is cited more often in the public health ethics literature than John Stuart Mill's essay "On Liberty" [10]. In that essay, Mill defends what has come to be called the harm principle, in which the only justification for interfering with the liberty of an individual, against her will, is to prevent harm to others. The harm principle is relied upon to justify various infectious disease control interventions including quarantine, isolation, and compulsory treatment. In liberal democracies, the harm principle is often viewed as the most compelling justification for public health policies that interfere with individual liberty $[10,19]$. For example, a prominent view in the United States is that it was not until the public became persuaded of the harmful effects of "second hand smoke" that the first significant intrusion into smoking practices - the banning of smoking in public places-became politically possible. Perhaps because of the principle's broad persuasiveness, it is not uncommon to see appeals made about harm to others in less than obvious contexts [11]. Defenders of compulsory motorcycle helmet laws, for example, argued that the serious head injuries sustained by unprotected cyclists diverted emergency room personnel and resources, thus harming other patients[12, 32]. The harm principle has been interpreted to include credible threat of significant economic harm to others as well as physical harm. Regarding smoking policy, various restrictions on the behavior of smokers have been justified by appeal to the financial burden on the health care system of caring for smoking-related illnesses [13].

As with all such principles, questions remain about its specification. How significant must the threat of harm be, with regard to both its likelihood and magnitude of effect? Are physical harms to the health of others to be weighted more than economic harms or other setbacks to interests? Whether interpreted narrowly or broadly, there are limits to the public health cases that can plausibly be placed in the harm principle box [14, 15]. Moreover, in the context of 
commitments to social justice and general welfare, and the other justifications described above, too exclusive a focus on the harm principle can undermine otherwise justifiable government mandates and regulation. It is undeniable that individuals have much broader and more multidimensional interests than narrowly self-directed physical ones, and in that sense, it is not unreasonable to have a fairly expansive understanding of "harm" in a public health context [16-18]. The summary of the fundamental ethical principles and their applications in public health and biomedical research illustrated by Chilengi [17], is shown in table 1.

\begin{tabular}{|c|c|c|}
\hline PRINCIPLES & DESCRIPTION & APPLICATION \\
\hline AUTONOMY & $\begin{array}{l}\text { Human beings are born as } \\
\text { autonomous agents. This autonomy } \\
\text { gives them the rights to self } \\
\text { determination that must be respected. } \\
\text { Autonomy demands that the wishes of } \\
\text { all persons must be respected and we } \\
\text { do so by asking their opinion or } \\
\text { willingness to get involved or not }\end{array}$ & Informed Consent \\
\hline NON-MALEFICENCE & $\begin{array}{l}\text { Primun non nocere, Latin translation } \\
\text { for first, do no harm. Research must } \\
\text { primarily and actively seek not to do } \\
\text { harm regardless of the extent of } \\
\text { potential good that may arise from the } \\
\text { research. }\end{array}$ & $\begin{array}{l}\text { Evaluate foreseeable risks and } \\
\text { minimize harm }\end{array}$ \\
\hline BENEFICENCE & $\begin{array}{l}\text { While minimizing harm research must } \\
\text { be of benefit to individuals and society } \\
\text { at large. Beneficence is a group of } \\
\text { norms for providing benefits and } \\
\text { balancing benefits against risks and } \\
\text { costs }\end{array}$ & Maximize benefits \\
\hline JUSTICE & $\begin{array}{l}\text { A group of norms for distributing } \\
\text { benefits risks and costs fairly. The } \\
\text { benefits of research must equitably be } \\
\text { shared by those who bore the cost and } \\
\text { risk of the research. }\end{array}$ & $\begin{array}{l}\text { Fair subject selection and fair } \\
\text { distribution of benefits. }\end{array}$ \\
\hline
\end{tabular}

Table 1. Summary of fundamental ethical principles and their applications in public health and biomedical research [17].

\section{Some challenges related to public health research ethics}

There is no standardized method of organizing either the ethics of clinical practice, or the public health and biomedical research. Although these distinctive concerns are often dealt with under 
the broader term of bioethics, sometimes bioethics is presented as the equivalent of medical ethics. Whichever approach is preferred, a key question remains: what distinguishes public health ethics from medical ethics? The answer lies in the distinctive nature of public health $[23,51]$.

Public health has four characteristics that provide much of the subject matter for public health ethics as follows: (1) its promotion involves a particular focus on prevention; (2) it is a public or collective good; (3) it involves an intrinsic outcome-orientation and (4) its promotion often entails government action; [11, 24-26].

First, in public health the main point of concern is the population, not individuals. Public health is, by its very nature, a public, communal good, where the benefits to one person cannot readily be individuated from those to another, though its burdens and benefits often appear to fall unevenly on different sub-groups of the population [25]. This raises a particular set of challenges the public health ethics has to address. Whose health are we concerned about, and then what sacrifices is it acceptable to ask of individuals in order to achieve it? Is there a difference between public health and population health? And why is public health a good worth promoting? [26]. Any answer to these questions has to take into account the fact that public health measures are often based on the prospect of benefit to individuals, not immediately securable benefits $[23,27]$.

Second, promoting public health involves a high degree of commitment to the prevention of disease and injury. However, although much of the discussion surrounding public health focuses primarily on this preventive aspect, public health agencies and services also involve diagnosing and treating illnesses, with all the attendant clinical services that those activities require $[28,29]$.

Achieving good public health results frequently requires government action: many public health measures are coercive or are otherwise backed by the force of law. Public health is focused on regulation and public policy, and relies less often on individual actions and services. In this as in all other areas of official state action, we therefore have to address tensions among justice, security, and the scope of legal restrictions and regulations [19, 30].

\subsection{The rationale of public health programs and policies}

Public health draws its fundamental legitimacy from the essential and direct role that health plays in human flourishing, whether that role is understood ultimately in terms of maximizing health or promoting health in the context of advancing social justice [31,38]. This general justification is sometimes too broad, however, to provide sufficient moral warrant for specific public health policies and institutions, especially when, as is so often the case, these policies and institutions are implemented by the state and affect the liberty or privacy of corporate or individual persons (Beauchamp, 2010). This section puts forward six justifications or reasons that can be put forward to defend a particular public health institution or policy [32].

Two observations are worth making at the outset. First, public health policies are rarely defended by only one reason. Usually a mixed set of justifications can be provided. For 
example, tax policies intended to decrease cigarette consumption can be defended both by appeal to paternalism and by appeal to reducing the harms of second hand smoke to children in the home and in automobiles[20,33]. Second, the impact of public health policies is often not uniform across all the individuals affected by the policy, and thus different justifications are sometimes put forward specific to these different people. This complexity is unavoidable, since it results from the nature of public health: The focus of public health is population health, but populations are rarely internally uniform with regard to all features that are morally relevant to any particular policy [28, 34-35]. Some people may stand to benefit from the policy while others may not. Moreover, in line with concerns about democratic legitimacy and state over-reaching, some members of the population may support the aims of the policy while others may object [36].

The first four of the justifications for public health policies- overall benefit, collective efficiency/ action, and fairness- speak specifically to the context in which some members of the affected population are not directly benefited by the policy or object to it [37]. The next two justifications appeal to the significance of harm, both to others and to oneself. They apply more specifically to traditional concerns about balancing respect for liberty with advancing health and are more prevalent in the public health ethics literature than the previous four. In the fifth justification, the argument is from a relatively uncontroversial Millian harm principle, and in the sixth justification, from somewhat more tendentious paternalistic principles [12, 38].

\subsection{Some benefits of public health}

It is difficult to estimate direct benefits of the majority of public health interventions since some of these interventions target many health problems and many interventions can contribute to reduce the burden of one health problem. Furtherer, it is known that some of health determinants like those associated to environment change naturally. At individual level, it is even more complicated as the efficacy of public health intervention is the absence of a particular health event that is difficult to justify by the intervention $[39,40]$.

Generally, we all benefit from having public health interventions, and from having trusted regulatory agencies such as the Centers for Disease Control and Prevention (CDC) or the Food and Drug Administration (FDA) make decisions about such interventions and their reach [16, 41]. All things considered, having public health regulation is better than not having it. Having public health decisions made on the basis of overall statistics and demographic trends is ultimately better for each one of us, even if particular interventions may not directly benefit some of us. Thus, the task of public health ethics is not necessarily to justify each particular intervention directly $[16,41]$. Rather, public health interventions in general, as long as they stay within certain pre-established parameters, can be justified in the same way a market economy, the institution of private property, or other similarly broad and useful conventions that involve some coercive action but also enable individuals to access greater benefits can be justified: when properly regulated and managed, its existence is by and large better than its absence for everyone [43]. 


\subsection{The public health policy action strategies}

A related justification views health as a public good the pursuit of which is not possible without ground rules for coordinated action and near-universal participation. The public health is viewed as having the structure of a coordination or collective efficiency problem. For example, if one person (or a sufficient critical mass of such persons) decides not to abide by a public health regulation because the regulation does not directly benefit he or she otherwise objects, the ramifications will likely be felt by others in her environment and beyond (Daniels, 2008). Everybody has to participate because, failing their involvement, neither they nor anyone else can reap the benefit of a healthy society (Crawford, 2008).

The collective efficiency class of arguments relies on claims about the sheer number and technical complexity of the decisions that need to be made to protect health in the environment and in the market place, as well as the indivisible character of responses to some health threats $[15,21,46]$.

\subsection{Public health community engagement}

The communitarian argument relies on the idea that is good for the whole is necessarily good for its parts [47]. Communitarians view individuals' identities and the meaningfulness of their lives as indelibly tied to the well-being of their community. Clinical research in a developing nation to be deemed ethical requires community engagement, so that the research can contribute to the social value. Thus, on this view, public health interventions are good for individuals simply because they benefit the community as a whole. It thus encourages a cooperative way of thinking about public health interventions. Its main shortcoming, however, is that it assumes too tight a connection between individuals and the communities to which they belong, thereby incurring the potential for abuses of less privileged individuals within certain communities in the name of communal well-being [48]. It is unfortunately not always the case that the interests of individuals and the interests of their communities coincide in this convenient way. Rather, such interests often come apart, and can come into conflict in ways that require us to address yet again the questions: how much can we ask of individuals for the sake of others, of which individuals can we ask sacrifices for the sake of the community, and why? There is a conceptual distance between what is good for particular individuals, what is good for all individual members of a community, and what is good for the community $[8,49]$. Thus, there can sometimes be direct trade-offs between what is good for the community and what is good for particular individuals within it. Notwithstanding these difficulties, this is certainly a strategy worth giving serious consideration as a possible avenue for the justification of public health interventions, particularly in some contexts where there is a strong sense of community solidarity $[3,50]$.

\section{Aspect of justice and fairness in public health}

Whether social justice is viewed as a side constraint on the beneficence-based foundation of public health, or as foundational in its own right, there is broad agreement that a commitment 
to improving the health of those who are systematically disadvantaged is as constitutive of public health as is the commitment to promote health generally (Powers and Faden 2006, Institute of Medicine's Committee for the Study of the Future of Public Health [50-52].

In this regard, there is an intimate connection between public health and the field of health and human rights. Many in public health accept that there is a fundamental right to health, as codified in the United Nations Universal Declaration of Human Rights or otherwise, although there is less agreement about the justification for such a right or what precisely the right entails [24]. A key question for public health ethics is on whom the duties generated by a right to health fall. Since so many of these duties require collective action. The governments are obvious candidates, but so, too, are other social institutions in the private sector as well as those global in structure that bear on the right to health $[8,35]$. A failure on the part of these institutions to ensure the social conditions necessary to achieve a sufficient level of health is an injustice that on the view of many violates a basic human right. Note that as a basic human right, the claims of the right to health are not in any fundamental respect restricted to national borders but rather fall on the human community [9].

When inequalities in health exist between socially dominant and socially disadvantaged groups, they are all the more important because they occur in conjunction with other disparities in well-being and compound them $[1,15]$. Reducing such inequalities are specific priorities in the public health goals of national and international institutions.

One of the most difficult challenges for public health ethics emerges when moral function conflicts with the injunction to improve, if not maximize, aggregate or collective health outcomes [39]. Although the health of the world's most desperately poor can in many cases be improved by extremely cost-efficient interventions like basic childhood immunizations and vitamin supplementation, reducing other unjust inequalities in health can consume significant resources.

Another challenge in social justice for public health ethics emerges when the health needs of systematically disadvantaged groups conflict with other dimensions of well-being as well as with considerations of collective efficiency. Targeting a public health program to poor and minority communities can sometimes both serve social justice concerns and be efficient if, for example, the health problem the intervention targets occurs disproportionately in these groups $[7,42]$. At the same time, however, if the health problem is itself associated with stigma or shame, targeting the poor and minorities may reinforce existing invidious stereotypes, thereby undermining another critical concern of social justice, equality of social respect. In such cases, public health authorities must decide whether a commitment to social justice requires foregoing an efficient, targeted program in favor of a relatively inefficient, universal program that also may produce less improvement in health for the disadvantaged group (thus failing to narrow unjust inequalities) in order to avoid exacerbating existing disrespectful social attitudes [19].

Some formal methods, including most notably cost-utility analysis, rely on what are referred to as summary health measures in which mortality and diverse morbidities are combined in a single metric such as a quality-adjusted or disability-adjusted life year. These measures, and 
the formal methods that employ them, sometimes rely on assessments of what may be only vague individual preferences for trade-offs between different states of health or different kinds of benefits. Moreover, they make morally problematic assumptions including, for example, whether to differentially value years saved in different stages of life and about how to disvalue specific disabilities [34]. Depending on how these and other assumptions are determined and specified, summary health measures have been criticized as being ageist or not ageist enough, as discriminating unfairly against people with disabilities, as failing to capture the moral uniqueness of life-saving, as treating as commensurable qualitatively different losses and benefits, and as failing to take adequate account of the claims of those who are most disadvantaged $[14,50]$.

\subsection{Burden distributions in ethical research}

Another appeal that can be used to defend certain public health interventions that impose unequal burdens on different members of a population relies on considerations of fairness. The basic premise of this line or argument would be that burdens have to be roughly equivalent for everyone [23]. The same could be said for certain public health "burdens," understood as both the burdens of disease and disability and the burdens of public health interventions. Based on considerations such as a particular group's likelihood to contract a certain disease, and their overall health status, other parts of the population can legitimately be asked to "contribute," as it were, in order to make the distribution of disease burdens more equitable $[9,50]$. For example, part of the rationale for requiring child immunization prior to enrollment in school is that this is a way to ensure that low-income children, who are generally less healthy than other children, have access to the needed vaccines [44]. Another example of public health interventions that appear to be guided by this justification is rubella vaccination of children for the sake of pregnant women and their fetuses [50]. This reasoning can help explain why individuals are sometimes asked to bear public health burdens that do not directly benefit them. However, the question of how far we can go in redistributing health-related burdens will likely continue to plague any proponent of this justificatory strategy. Moreover, questions about the plausibility of viewing health-related burdens as subject to distribution in this manner may also arise $[6,17]$.

\subsection{Paternalism}

Paternalism is classically understood as interfering with the liberty of action of a person, against his/her will, to protect or promote his/her welfare is as controversial as the harm principle is uncontroversial (Dworkin 2005). Few public health interventions are justified exclusively or even primarily on unmediated, classic paternalistic grounds, although many more public health programs may have paternalistic effects. By contrast, other classes of arguments that are sometimes described as paternalistic, including soft paternalism, weak paternalism, and libertarian paternalism, are evoked more frequently [19, 21].

Soft and weak paternalism are usually interpreted as interchangeable, though they have sometimes been taken to denote different concepts [14, 46]. A common interpretation defines this kind of paternalism as interferences with choices that are compromised with regard to 
voluntariness or autonomy. Though a person might voice or hold a preference different from the one that is sought for him, his preference is not entitled to robust respect if it is formed under conditions that significantly compromise its autonomy or voluntariness, such as cognitive disability or immaturity and, in very limited cases, ignorance or false beliefs [20]. Adaptive preferences are also considered compromised with regards to autonomy: sometimes, individuals modify their preferences in order to be able to adapt to difficult, unjust, or undesirable circumstances [32]. Such preferences also do not have the same standing as preferences formed under normal conditions and are therefore viewed as subject to interference [32].

Libertarian paternalism defends interventions by planners (such as public health authorities) in the environmental architecture in which individuals decide and act in order to make it easier for people to behave in ways that are in their best interests (including their health), provided two conditions are satisfied [5,31]. First, individuals are steered by these interventions in ways that make them better off, as judged by themselves. Thus, in libertarian paternalism there is no attempt to contravene the will of individuals, in contrast to what some hold to be a necessary feature of paternalism. Second, the interventions must not overly burden individuals who want to exercise their freedom in ways that run counter to welfare. In this sense, libertarian paternalism claims to be liberty-preserving, hence libertarian.

A key conceptual question about paternalism is whether the interference with individual liberty must be against the person's will [3]. If this feature is a necessary condition of paternalism, then libertarian paternalism is inappropriately titled. From the standpoint of public health ethics, however, whether libertarian paternalism is appropriately titled is less important than the moral issues it raises and how it is justified $[1,52]$.

\subsection{Mutual benefit}

Finally, there is a more pragmatic reason to attend to public health in the developing world. Beyond claims of justice, morality, and common decency, we live in a world where mobility and interaction within and across countries is very high. Diseases such as SARS, H1N1, and drug-resistant $\mathrm{TB}$, as well as less headline-grabbing ailments such as cholera and malaria, are not neatly contained within one national boundary. Citizens of all countries would benefit from improving public health in the developing world. Contributing to the availability and improvement of medical, sanitary, and other health-related resources for those who live in poverty and deprivation is ultimately good for us all, whether we are in the habit of traveling around the world or not [7]. There is also the need for understanding the emerging diseases and those poverty related diseases that is of major economic concerns [36, 52].

\section{Research for low income ecomomies}

Medical research is sometimes undertaken in the low income economies in order to further the understanding and treatment of diseases, not primarily for the benefit of those in the developing world, but rather for the benefit of citizens of the developed world. In such cases, 
participants and their communities might well claim that they are entitled to share in the benefits of the research $[9,16]$. However, compensation to participants and their communities is often non-existent or not nearly in line with the potential benefits their participation will bring to those fortunate enough to have been born in a different geographical location [6, 36]. Note that this is a different issue from the question of whether researchers working on indigenous diseases in the developing world have a duty to provide medical care or other ancillary services to their research subjects $[5,21]$.This is less a question of justice as of research ethics more generally.

\subsection{Uneven research focus}

Much medical research is focused on diseases that affect less than $10 \%$ of the world's population, while millions die every year from diseases that potentially could be prevented or more easily treated if only enough research and other medical resources were devoted to them [1, 20]. Given the sheer numbers of people who needlessly die every day from such neglected but widespread diseases, and given that the developed world clearly has the resources to change that state of affairs, justice claims arguably also arise in this context [22, 35].

\subsection{The legal compensatory claims}

Many poor, underdeveloped countries that are massively underserved when it comes to public health resources continue to suffer from the direct and indirect effects of historical, unjust harms perpetrated by many of the world's wealthiest countries such as colonialism, war, occupation, and other forms of violent economic exploitation [36, 43]. In many cases, harms are more recent or are continuing, for example the diamond wars in Sierra Leone and other African countries as well as the more general on-going exploitation of local natural resources. Both the historical effects and the persistent effects of such violence and exploitation on public health in those countries ground additional justice-based claims against the wealthy nations to reduce the profound inequalities in health that exist between the world's poor and advantaged people $[8,26]$.

\subsubsection{The role of the ethics committee}

There are many synonymous for committees that review and approve biomedical research protocols to safeguard the dignity, rights, safety and well being of actual or potential research participants (WHO, 2000; Tedlock, 1983).Terminologies such as Independent Ethics Committee (IEC), Institutional Review Boards (IRB), Institutional Ethics Committee (IEC), National Ethics Committee (NEC) and Ethics Review Boards (ERB) are interchangeably used. The two WHO guidelines have addressed in details the description of what ERB are, or are intended to be, recommended compositions, what ethical review entails, how they should operate, reach decisions and communicate those decisions. Other publications have provided ethical framework for evaluating whether proposed research is ethical (CIOMS, 2008, Emmanuel et al., 2000; Amdur and Elizabeth, 2002. It is important therefore to look at the different roles of stakeholders in ethical research. 


\section{Responsibilities of the participants}

The greatest role of ERB is to ensure that research that is conducted among the communities is ethical. Also important to this obligation is to ensure that in its basic setup, composition, operations and follow up activities are such that the mandate of protecting research participants is carried out effectively.

\section{Research and legal liability}

Legal liability claims against health professionals were traditionally confined to those who engaged in clinical practice. However, in recent years an increasing number of civil claims have emerged in the health research realm. In this regard, three trends have emerged: (1) the types of legal claims have diversified; (2) the number and types of defendants named in such lawsuits have increased beyond researchers; and (3) class action lawsuits are increasingly being lodged on behalf of groups of research subjects (Mello et al., 2003). While the overwhelming number of research-related lawsuits has arisen in affluent countries, the filing of multi-jurisdictional lawsuits against drug maker, Pfizer, in relation to its Trovan drug trial in Nigeria illustrates that developing countries are also becoming battlegrounds from lawsuits against those involved in research. This work outlines the liability risks of researchers, host institutions, research ethics committees, consulting bioethicists, and research sponsors through a review of sample cases involving these parties.

There exist a number of liabilities in the ethical conduct of research involving all the stakeholder that can be outline as follows:

\section{Research liability}

This involves civil claims against researchers which in the early days centered around the notion of informed consent If we consider the case of Wess versus Solomon (1989), the heirs of a subject who died while a volunteer in a non therapeutic study successfully sued the investigator and his university-affiliated hospital. The judge found the principal investigator and hospital, through its research ethics committee responsible for not disclosing a rare fatal complication caused by fluorescent dye and not adequately screening the subject who suffered from undisclosed hypertropic cardiomyopathy.

\section{Research ethics committee liability}

Research ethics committee (RECs) or Institutional Review Boards (IRBs), are responsible for assessing human research protocols for conformity to ethical principles (Zlotnik Shaul, 2002). RECs liability has been recognized as far back as in the 70s, when the US National Commission for the protection of Human Subjects of Biomedical and Behavioral research published a report captioned Report and Recommendation: Institutional Review Board (NCPHSBBR, 1978).The principles state that one who undertakes to protect others must act responsibly. IRB members could be liable if they did not exercise reasonable care in carrying out their review. This may occur if their approval led to a research activity and injuries that would not have occurred if a reasonable person, confronted with the same information would have placed conditions on the research that would have prevented the injury. Therefore an injured can possibly press charges for negligence by the IRB members in assessing the risks and benefits of proposed 
research, or in approving consent procedures not necessarily likely to assure legally effective consent.

\subsubsection{Institutional liability}

Institutional liability arises from the Common Law doctrine of vicarious liability, which holds superiors accountable for the wrongs of their subordinates (Amir, 2009). Amir JA. Research and Legal Liability. Acta Tropica, 2009;112S:S71-S75).An illustrated case is that in the US of Berman versus Fred Hutshinson cancer centre (2002) where the husband of a research participant (Hamilton) died in a chemotherapy trail brought filed a law suit against the Fred Hutchinson Cancer Centre alleging that his wife's consent to participate in the study was not informed because the institution failed to disclosed the following:

That the researchers had no idea whether the relevant drugs would have any protective effect against organ damage; Hamilton would not receive the planned dosage of the drug if she were unable to ingest the oral version of the drug; seven prior protocol participants had died, one of whom had suffered serious organ damage; and there were alternative treatments that were less risky and were reporting a significantly higher cure rate. In summary Berman argued that his diseased wife did not give informed consent to participate in the trial as she was not informed that an experimental drug to prevent lethal side effects of chemotherapy was not available was not available in the intravenous form. After trying to swallow the pills, the participant vomited the pills and died. The trial court handling the case ruled that the Fred Hutchinson Cancer Research Centre's failure to disclose the unavailability of the intravenous form of the drug invalidated Hamilton's consent to participate in the trial.

\section{Bioethicist liability}

The bioethicist liability case can be exemplified in the Robertson case where the plaintiffs' alleged that the consulting bioethicist in the matter was careless, negligent and reckless for the following: failing to exercise reasonable care under all of the circumstance, in accordance with the accepted bioethical practice; failing to follow and abide by by the guidelines set forth by various governmental agencies and acting negligently.

\section{Sponsor laibility}

The most high profile lawsuit filed against a study sponsor are those lodged against the US pharmaceutical firm, Pfizer, y the Nigerian plaintiffs and authorities. The lawsuits arose from a 1996 drug study conducted by Pfizer in the Northern State of Kano during a meningitis epidemic. In the US case of Abdullahi versus Pfizer Inc (2003), the plaintiffs, parents of the child participants in the trial, alleged the use of the drug TROVAN on children with meningitis was done without the parental informed consent and resulted in nearly a dozen dying, and others being left with brain damage, paralysis and slurred speech. In January 2009, the US Court of Appeals for the Second Circuit in New York overturned a lower court's finding that the cases brought by the plaintiffs could not be heard in the United States (Perlroth, 2009). In April 2009, Pfizer reportedly settled the case for $\$ 75$ million (Howden, 2009).However, the settlement of the US case did not affect other pending cases against Pfizer in Nigeria such as the $\$ 7$ billion case lodged by the Nigeria Federal Government in June 2007 and a $\$ 2$ billion case 
lodged by the Kano State Government (Sturcke, 2007).The Pfizer case is significant for various reasons. To begin with, it illustrates that research participants in the developing countries are gaining increasing awareness of their rights and are prepared to act accordingly. The second point is that research conducted by US sponsors of research in developing countries is actionable against those sponsors in the US. Thirdly, research liability lawsuits may also be brought by government authorities, even though they were not the affected parties. Lastly, liability suits may be filed concurrently in different countries and a judgment or settlement in one country does not affect pending cases elsewhere. Some countries require sponsors and investigators to obtain insurance coverage for trial participants for trial-related injuries as a prerequisite to trial commencement. The Pfizer case demonstrates that it is important for sponsors and investigators to have insurance cover clinical drug testing trials.

There exist other potential areas of law suit given the increase in multi-country, multi-national collaborations. Potential lawsuits are emerging from legal issue with material transfer agreement, data sharing agreement and intellectual property rights. The use and storage of biological materials/samples, particularly those exported for storage and analysis to institutions in sponsor countries for use such as to determine biomarkers that confer protective immunity where capacity to conduct such analysis is not available in host countries in the developing countries. Solutions to solving such potential problems involve signing contractual agreements, memoranda of understanding such as data sharing agreement (DSA), Material Transfer Agreement (MTA), entered into between the disputing parties. Such agreements should be negotiated between all relevant stakeholders before any clinical research can commence, and that a dispute resolution mechanism are jurisdictional issues are prospectively determined in the case of any foreseeable dispute.

\subsection{Contribution of International Research Integrity (IRI) in public health research promotion}

National Science Foundation NSF implementation of Section 7009 of the America Creating Opportunities to Meaningfully Promote Excellence in Technology, Education, and Science (COMPETES) Act requires that the Authorized Organizational Representative complete a certification at the time of proposal submission that the institution has a plan to provide appropriate training and oversight in the responsible and ethical conduct of research to undergraduates, graduate students, and postdoctoral researchers who will be supported by NSF to conduct research. Additional information on NSF's responsible conduct of research (RCR) policy is available in the Award and Administration Guide, Chapter IV.B [46]. While training plans are not required to be included in proposals submitted to NSF, institutions are advised that they are subject to review upon request.

With the increasing globalization of science and engineering research and education, and the associated issues related to the responsible conduct of research within a global context, NSF recognizes that projects involving international partners may present special risks and challenges. Maintaining high standards of ethical and scientific integrity helps to maintain public trust in the research enterprise. An increasing number of authors have pointed to the importance of mentoring and education in relation to the responsible conduct of science in 
preventing transgressions of scientific integrity. Just like in clinical research and biomedicine, epidemiologists and other public health researchers have the responsibility to exhibit and foster the very highest standards of scientific integrity [46]

The following resources are provided to assist in developing training and oversight plans for the responsible and ethical conduct of research in an international context and to understand the codes of conduct in other countries. NSF does not provide content or endorse these sites' content, but provides them as possible resources.

\subsection{National institute of health in public health research clinical excellence}

The National Institute for Health and Clinical Excellence (NICE) is a special health authority of the English National Health Service (NHS), serving both English NHS and the Welsh NHS. It was set up as the National Institute for Clinical Excellence in 1999, and on 1 April 2005 joined with the Health Development Agency to become the new National Institute for Health and Clinical Excellence (still abbreviated as NICE). NICE carries out assessments of the most appropriate treatment regimes for different diseases. This must take into account both desired medical outcomes (i.e. the best possible result for the patient) and also economic arguments regarding differing treatments. NICE have set up several National Collaborating Centres bringing together expertise from the royal medical colleges, professional bodies and patient/ carer organizations which draw up the guidelines [47]. The centres are the National Collaborating Centre for Cancer, the National Clinical Guidelines Centre for Acute and Chronic Conditions, the National Collaborating Centre for Women and Children's Health, and the National Collaborating Centre for Mental Health. The National Collaborating Centre then appoints a Guideline Development Group whose job it is to work on the development of the clinical guideline. This group consists of medical professionals, representatives of patient and carer groups and technical experts. They work together to assess the evidence for the guideline topic (e.g. clinical trials of competing products) before preparing a draft guideline. There are then two consultation periods in which stakeholder organizations are able to comment on the draft guideline. After the second consultation period, an independent Guideline Review Panel reviews the guideline and stakeholder comments and ensures that these comments have been taken into account. The Guideline Development Group then finalizes the recommendations and the National Collaboration Centre produces the final guideline. This is submitted to NICE who then formally approve the guideline and issues this guidance to the NHS [47].

\subsection{Institute of tropical medicine and hygiene in public health research ethics}

The London School of Hygiene and Tropical Medicine is an institution promoting research in public health through the introduction of research training courses which aim at equipping students with skills needed to appreciate and analyze public health problems in developing countries, and to design and evaluate actions to improve public health. The course considers issues of global health, development and the provision of health services from a multidisciplinary perspective. All the public health students are expected to have a substantial experience of planning or implementation of public health programmes, of teaching or research, in developing countries. Graduates from this course work in global health, health service 
management, in health programmes in developing countries, in international and national NGOs, and in research. In addition to MSc Public Health in Developing Countries. By the end of the course students should be able to: demonstrate knowledge and understanding of theory and practice in the core public health disciplines (epidemiology, statistics, social sciences, health policy and health economics; demonstrate specialized knowledge and skills in other areas relevant to public health from a wide range of options (e.g., primary health care, medical anthropology, epidemiology and control of malaria, and population studies); apply these skills to identify and assess public health problems in developing countries and evaluate actions designed to improve public health; formulate public health strategies and approaches to public health problems appropriate to a given culture and environment; and apply appropriate research skills for evaluation and use of research findings.

\subsection{World Health Organization (WHO) in public health research ethics}

Health ethics has been an integral part of the activities of many units and departments at WHO for many years and is addressed not only within the Department of Ethics and Social Determinants (ESD) and throughout the organization. ESD works collaboratively with staff from all departments and the regional offices to identify, design, and carry out projects addressing the ethics of health care, public health, and biomedical science. This encompasses projects that originate in the department and those on which it provides advice and assistance to activities located in other clusters and in regional offices. In October 2002, the World Health Organization launched its Ethics and Health Initiative to provide a focal point for the examination of the ethical issues raised by activities throughout the organization, including the regional and country offices, and to develop activities regarding a wide range of global bioethics topics, from organ and tissue transplantation to developments in genomics, and from research with human beings to fair access to health services.

Work in ethics and health is now carried out by the Department of Ethics and Social Determinants in the Innovation, Information, Research and Evidence cluster at headquarters. This department is involved in a wide range of ethics activities, both on its own initiative and in response to the needs of other parts of WHO. The specific projects, many of which link different departments and involve experts from outside the organization, evolve in response to changes in the field.

\subsection{NEPAD in promoting public health research in Africa}

The New Partnership for Africa's Development (NEPAD) is a socio-economic development programme of the African Union (AU) whose express objective is to stimulate Africa's development by bridging existing gaps in Infrastructure (Energy, Water and Sanitation, Transport and ICT); Agriculture and Food Security; Human Resource Development, especially Health/Education, Youth and Training, Social Affairs; Science, Technology and Innovation; Trade, Industry/Market Access and Private Sector Development; Environment/Climate Change and Tourism; Governance/Public Administration, Peace and Security; Capacity 
Development, and Gender Development. The implementation of these programmes is based on the AU/NEPAD principles of African leadership and the ownership of the continent's development agenda and process, as well as a commitment to good political, economic and corporate governance. African leaders have explicitly recognized that socio-economic transformation of the continent cannot be achieved without increased investments in science, technology, and innovation. To that end, the leaders have initiated a number of concrete actions geared towards promoting the continent's scientific and technological development. The actions include the creation of the African Ministerial Council on Science and Technology (AMCOST) and its subsidiary bodies -- the NEPAD Office of Science and Technology, and the AU Commission for Human Development, Science and Technology. These institutions have collectively developed a comprehensive strategy and action plan -- Africa's Science and Technology Consolidated Plan of Action -- adopted at the second African Ministerial Conference on Science and Technology in Dakar, Senegal, in September 2005. The main goals of Africa's Science and Technology Consolidated Plan of Action (CPA) are to strengthen Africa's capacities to develop, harness and apply science, technology, and innovation to achieve millennium development goals (MDGs), as well as mobilizing the continent's expertise and institutions to contribute to the global pool of science and technological innovations. Key to these goals is the promotion of transnational Research and Development (R\&D) programmes

\subsubsection{Technological trends and Innovation systems in public health delivery in Africa}

There is need for a common and shared understanding of what can be done in order to tap science, technology and innovation tools to address Africa's current huge burden of disease. First, African countries and institutions have to show the qualities of leadership necessary for generating and utilizing technology and innovations in health in order to address diseases that are peculiar to this continent. It is evident that many of these diseases are not being addressed by the global scientific community for reasons which need no enumerating here. This can only be Africa's responsibility. Secondly, Africa needs to position itself strategically with regard to shaping and driving a new research and innovation agenda necessary for disease treatment and diagnosis. Today, the continent does not have access to relevant health innovation tools that are widely available around the world. Worse still, Africa is not a key player in the public health research and innovation enterprises. Inequality in science, technology and health innovation capacity in Africa is evident in the extent of the disease burden in many countries. Consequently, the current global funding arrangements for public health, including for global pandemics like HIV/AIDS and neglected diseases, must go beyond merely treating the symptoms through the provision of treatment but should also focus on building requisite health research and development [53] infrastructure on the continent. Thirdly, new continental initiatives must focus on shifting the apparent successes in health innovations to product development and product delivery. It is evident that while promising innovations have been developed in Africa and/or for Africa's specific diseases, not many investments are taking place in product development and product delivery. It is therefore important to address this shortcoming in the context of the Africa health strategies for NEPAD and the AU. 
Finally, Africa must take advantage of the wide pool of scientific knowledge and technology tools available globally. This means that, on the one hand, individual countries and continental institutions must invest in technology prospecting in order to exploit existing and relevant health technologies and products. On the other hand, Africa must invest in setting up or transforming research institutions that are not only knowledge-based but also oriented towards product development. There is an immediate need to strengthen African institutions, especially universities and schools of medicine, by increasing funding and revising the curricula. Thus the issue of how science, technology and innovation can alleviate Africa's burden of disease.

\subsubsection{Ethics in European Union research}

Public attitudes towards science and technology are overwhelmingly positive. The confidence generated by messages such as 'scientifically tested' or 'scientifically proven' is testament to society's support of scientific endeavour. It also highlights the social responsibility that accompanies research. As science advances and evolves, and the relationship between science and society gets better explanations, new challenges are created for the scientific community. Nowadays, there are more scientists than ever before. On a regular basis, exciting research opportunities spring into existence. Grant driven projects and non funded projects are larger, more complex, and more expensive. The role that science plays in our lives continues to gain more significance and recognition in importance, and society, in turn, has a stake in science. Consequently, the relationship between science and society continues to change and intensify in the pursuit of progress [54].

Excellence in science means addressing ethical concerns - to improve the quality of the science itself, but also to highlight the importance of its outcomes to the wider community. The EU's commitment to ethics in research is reflected in explicit requirements, and more specifically in the evaluation of project proposals. Ethics may be context-dependent, but any research team's approach to ethical matters is taken as an indication of the honesty and the clarity of its proposal. While there are rarely clear-cut answers when it comes to ethics, some areas are excluded from EU funding by definition. These are human cloning for reproductive purposes, altering the genetic heritage of human beings, and creating human embryos only to conduct research or obtain stem cells [54].

\section{Conclusion}

The population of low income economies are highly vulnerable in medical research. The fundamental ethical principles need to have its place in the global public health research sectors. With the increase research in finding new investigational products, developing new disease diagnostics techniques puts the human population into a vulnerable position vis a vis participation into clinical research trials. It is therefore imperative for the public health sector to place more emphasis in the implementation of research that is ethical. By so doing the fundamental principle of morality, autonomy and respect for others, beneficence, non- 
maleficence and justice shall be practicable and sustainable as within the universal declaration of Helsinki. The public health sector in both developing and developed nations has a duty to set up a working platform that may reduce the 10/90 gap that has remained static in the subSaharan Africa. Medical research should be undertaken in the low income economies in order to further the understanding and treatment of poverty related diseases, primarily for the benefit of those in the developing world, not rather for the benefit of citizens of the developed world. Ethics is therefore a non negotiable principle and policy in Public Health Clinical Research practice. It is also evident with increasing clinical research that there shall be more potential legal issues. This calls for more scrutiny in the institutions that be in regulating the ethical framework in the conduct of human research. Those implicate in research should ensure that they are fully versed with their legal rights and obligations associated with the research they are engaged in, and also in tuned with the import and export regulations relevant to biological material transfer, data sharing as the shortcoming of these regulation are potential points for legal liability.

\section{Acknowledgements}

We wish to acknowledge the special financial grant from the Ministry of Higher Education of Cameroon, the EDCTP Grant award to the National Ethics Committee of Cameroon, and the financial support from the University of Bamenda. All contributed to the research and processing of this invited write-up by INTECH Publishers.

\section{Author details}

C. N. Fokunang, ${ }^{1,2}$, E. A. Tembe-Fokunang ${ }^{1}$, P. Awah ${ }^{3}$, M. Djuidje Ngounoue ${ }^{2,4}$, P. C. Chi ${ }^{2}$, J. Ateudjieu ${ }^{1,5}$, R. Langsi ${ }^{6}$, Lazare Kaptue ${ }^{2}$ and O. M. T. Abena ${ }^{1}$

1 Faculty of Medicine and Biomedical Sciences, University of Yaounde 1, Centre Region, Cameroon

2 Cameroon National Ethics Committee (CNEC), Yaoundé, Cameroon

3 Faculty of Arts and Modern Letters, University of Yaoundé 1. Ipas, Chapel Hill, North Carolina, United States

4 Faculty of Sciences, University of Yaoundé 1, Centre Region, Cameroon

5 Faculty of Sciences, University of Dschang; Division of Health Operations Research, Ministry of Public Health Cameroon, Cameroon

6 Health Division, University of Bamenda, Cameroon 


\section{References}

[1] Barrett DH, Bernier RH, Sowell AL. Strengthening public health ethics at the centers for disease control and prevention.; Centers for Disease Control and Prevention Public Health Ethics Committee Steering Group. Journal Public Health Management Practice. 2008:.14(4):348-53.

[2] Beauchamp, T.L., Childress, J.F. Principles of Biomedical Ethics, $5^{\text {th }}$ edition Oxford University Press.2001 p.133.

[3] Beauchamp, T. The concept of paternalism in biomedical ethics. In Beauchamp, T. Standing on principles. New York: Oxford University Press. 2010: (pp. 101-119).

[4] Beecher, H.K., Ethics and Clinical Research. New England Journal of Medicine.1966: 274, 1354 .

[5] Belsky, L., and Richardson, H. S. Medical researchers' ancillary clinical care responsibilities. British Medical Journal, 2004: 328(7454), 1494-1496.

[6] Benatar, S. R. Reflections and recommendations on research ethics in developing countries. Social Science and Medicine, 2002: 54(7), 1131-1141.

[7] Bernheim, R.G., Melnick, A. Principled leadership in public health: integrating ethics into practice and management. Journal Public Health Management Practice. 2008: 14(4):358-66.

[8] Bernheim, R.G. Public health ethics: the voices of practitioners.J Law Med Ethics. 2003:31(4 Suppl):104-9.

[9] Beskow, L.M., Namey, E.E., Cadigan, R.J., Brazg, T., Crouch, J., Henderson, G.E., Michie M., Nelson, D.K., Tabor, H.K., Wilfond, B.S. Research participants' perspectives on genotype-driven research recruitment. Journal of Empirical Research for Human Research Ethics.2011: 6(4):3-20.

[10] Bhan, A., Jerome, A., Singh, R., Upshur, E.G., Grand Challenges in global health: engaging civil society organizations in biomedical research in developing countries. PLoS Med, 2007:. 4 (9), e272, www.plosmedicine.org.

[11] Bhutta, Z.A., Ethics in international health research:a perspective from the developing world. Bulletin WHO, 2002: 80:114-120.

[12] Buchanan, D. R. Autonomy, paternalism, and justice: Ethical priorities in public health. American Journal of Public Health, 2008: 98(1), 15.

[13] Büken NO, Büken E.The legal grounds regarding clinical trial in Turkey.Medical Law. 2011: 30 (4) : 591-611. 
[14] Cadigan, R.J., Michie, M., Henderson, G., Davis, A.M., Beskow, L.M.. The meaning of genetic research results: reflections from individuals with and without a known genetic disorder.J Empirical Research and Human Research Ethics. 2011: 6(4):30-40.

[15] Cambon-Thomsen, A., Rial-Sebbag, E., Knoppers, B.M..Trends in ethical and legal frameworks for the use of human biobanks.European Respiratory Journal; 2007 : 30(2):373-82.

[16] Childress, J. F., Faden, R. R., Gaare, R. D., Gostin, L. O., Kahn, J., Bonnie B. Public health ethics: Mapping the terrain. The Journal of Law, Medicine E Ethics, (2002:. 30(2), 170-178.

[17] Chilengi, R. An ethics perspective on responsibilities of investigators, sponsors and research participants. Acta Tropica, 2009: 112S:S53-S62.

[18] Cohen, J. T., Neumann, P. J., \& Weinstein, M. C. Does preventive care save money? Health economics and the presidential candidates. The New England Journal of Medicine, 2008: 358(7), 661-663.

[19] Council for International Organizations of Medical Sciences (CIOMS). International Guidelines for Biomedical Research Involving Human Subjects. Geneva. CIOMS. 2002. pp.112.

[20] Emanuel, E., Wendler, D., Killen, J., and Grady, C. What makes clinical research in developing countries ethical? the benchmarks of ethical research. The Journal of Infectious Diseases, 2004. 189(5), 930-937.

[21] Fineberg, H.VShattuck Lecture. A successful and sustainable health system--how to get there from here.North England Journal of Medicine 2012: 366(11):1020-1027.

[22] Gafni, A. Willingness-to-pay as a measure of benefits: Relevant questions in the context of public decisionmaking about health care programs. Medical Care. 1991: 29(12), $1246-1252$.

[23] Gitau-Mburu, D. Should public health be exempt from ethical regulations? Intricacies of research versus activity.East Africa Journal of Public Health., 2008: (3):160-162.

[24] Gollust, S.E., Baum, N.M., Jacobson, P.D. Politics and public health ethics in practice: right and left meet right and wrong.Journal of Public Health Management Practice. 2008: 14(4):340-347.

[25] Goodman, E. P. (2006). Stealth marketing and editorial integrity. Texas Law Review, $85,83-152$.

[26] Harper, I.. Translating ethics: researching public health and medical practices in Nepal., Canadian Journal of Public Health, 2006: 97 (5) : 402-424.

[27] Horstkötter D, Berghmans R, de Ruiter C, Krumeich A, de Wert G. "We are also normal humans, you know?" Views and attitudes of juvenile delinquents on antisocial 
behavior, neurobiology and prevention. International Journal of Law and Psychiatry. 2012:.35(4):289-97.

[28] Huddle TS. 2012. Honesty is an internal norm of medical practice and the best policy.American Journal of Bioethics. 12(3):15-27.

[29] Hyder, A. A., and Merritt, M. W. Ancillary care for public health research in developing countries. Journal of the American Medical Association, 2009: 302(4), 429.

[30] International Conference on Harmonization (ICH) Guidelines for Good Clinical Practice, 1996. Available freely on the websites and other sources.

[31] Jefferson, A.L., Carmona, H., Gifford, K.A., Lambe, S., Byerly, L.K., Cantwell, N.G., Tripodis, Y., Karlawish, J. Clinical Research Risk Assessment Among Individuals With Mild Cognitive Impairment. American Journal of Geriatrics and Psychiatry. 2012: $30.12-30$

[32] Jones, M. M., \& Bayer, R. Paternalism \& its discontents: Motorcycle helmet laws, libertarian values, and public health. American Journal of Public Health, 2007:. 97(2), 208217.

[33] Joyce, G.F., Carrera, M.P., Goldman, D.P., Sood, N., Physician prescribing behavior and its impact on patient-level outcomes.American Journal of Management Care. 2011: 17(12):62-71.

[34] Kass, N. E. An ethics framework for public health. American Journal of Public Health, 2001:. 91(11), 1776-1782.

[35] Kilama, W.L). The 10/90 gap in sub-Saaran Africa: Resolving inequities in health Research. Acta Tropica., 2009:112S:S8-S15.

[36] Kost, R.G., Lee, L.M., Yessis, J., Coller, B.S., Henderson, D.K. Assessing research participants' perceptions of their clinical research experiences.; Research Participant Perception Survey Focus Group Subcommittee. Clinical Translational Science. 2011: 4(6):403-413.

[37] Krech R..Working on the social determinants of health is central to public health. Journal Public Health Policy. 2012: 33(2):279-84.

[38] Lavery, J.V., Harrington, L.C., Scott, T.WEthical,social, and cultural considerations for the site selection for research with genetically modified mosquitoes. American Journal of Tropical Medicine and Hygiene. 2008: 79 (3), 312-318.

[39] London AJ, Kimmelman J, Carlisle B. Research ethics. Rethinking research ethics: the case of postmarketing trials.Science 4; 2012: 336(6081):544-555.

[40] Nicholas, J. Next steps in clinical trial redesign. Journal of National Cancer Institute. 2012:. 18;104(2):90-2. 
[41] New Partnership for Africa's Development (NEPAD). Science, Technology and Innovation for Public Health in Africa. In : Fetson Kalua, Abolade Awotedu, Leonard Kamwanja and John Saka editions: 2009, pp 213.www.nepadst.org.

[42] Nyika, A., Kilama, W., Chilengi, R., Tangwa, G., Tindana, P., Ndebele, P., Ikingura, J., Composition, training needs and independence of ethics review committees across Africa: are the gate-keepers rising to the emerging challenges? Journal of Medical Ethics, 2009:. 35, 189-193.

[43] Omonzejele, P.FIs the codification of vulnerability in international documents a sufficient mechanism of protection in the clinical research ethics context? Medical Law. 2011: 30(4):497-515.

[44] Reichert, T. A., Sugaya, N., Fedson, D. S., Glezen, W. P., Simonsen, L., \& Tashiro, M. (2001). The japanese experience with vaccinating schoolchildren against influenza. The New England Journal of Medicine, 344 (12), 889-896.

[45] Sade, R.M. Why physicians should not lie for their patients. American Journal of Bioethics.(2012:.12(3):17-9.

[46] Steven S C, Amyre B, Angus D. Ethics and Scientific Integrity in Public Health, Epidemiological and Clinical Research. Public Health Reviews, 2009, Vol. 34, No 1.

[47] Sorenson, C; Drummond, M; Kanavos, P; McGuire, A. National Institute for Health and Clinical Excellence (NICE): How does it work and what are the implications for the U.S.?. National Pharmaceutical Council. Retrieved 2009-09-18.

[48] Tangwa, G.B., Ethical principles in health research and review process. Acta Tropica, 2009:. 112S:S2-S7.

[49] Thomas, J.C., MacDonald, P.D., Wenink, E., Ethical decision making in a crisis: a case study of ethics in public health emergencies. : Journal Public Health Management Practice; 2009. 15 (2):E16-21.

[50] Thomas, J. C., Sage, M., Dillenberg, J., and Guillory, V. J. A code of ethics for public health. American Journal of Public Health, 2002: 92(7), 1057-1059.

[51] Wikler, D., and Brock, D. W. Population-level bioethics: Mapping a new agenda. In Dawson, A., and Verweij, M, Ethics, prevention, and public health, New York: Oxford University Press. 2007: p 78.

[52] World Medical Association Declaration of Helsinki, Available at http:// www.wma.net/e/policy/17-c-e.html. Ethical principles for Medical Research Involving Human Subjects. 52 ${ }^{\text {nd }}$ WMA General Assembly, Edinburgh, Scotland.

[53] Andanda P, Awah P, Ndebele P, Onigbogi O, Udatinya D and Mwondela M.The ethical and legal regulation of HIV-vaccine research in Africa: lessons from Cameroon, Malawi, Nigeria, Rwanda and Zambia, African Journal of AIDS Research 2011, 10(4): 451-463 ISSN 1608-5906 EISSN 1727-9445 
[54] Http://Cordis.europa.eu/fp7/ethics-en.htm/

[55] Abdullahi v Pfizer Inc., 77 Fed.Appx. 48 (2d Cir. 2003.

[56] Anderlik, MR. Legal Liability for Bioethics Involved in Research. Health Law and Policy Institute. http://www.law.uh.edu/healthlaw/perspectives/Research/ 001002Best.html/>(assessed 03/09/2012.

[57] Berman v Fred Hutchinson Cancer Centre Case No C01-0727L (BJR), August 8, 2002. United States District Court Western District of Washington at Seattle. Accessible: http://biotech.law.Isu.edu/research/wa/Berman_v_Hutchinson.pdf/_ (accessed 03/09/2012.

[58] Mello MM., Joffe S. Compact versus contract-industry sponsor's obligations to their research subjects. Ann. Intern. Med; 2003:43:231-561.

[59] Perlroth N. Pfizer's Nigerian Plaintiffs Get Day In Court, January, 2009 http:// www.forbes.com/2009/01/pfizer-nigeria-trovan-business-healthcare-0130_trovan.html/ accessed 03/09/2012.

[60] Robertson v McGee. No 01CV00G0H (M) (ND Okla filed January 29, 2001). Sherman, Silverstein, Kohl, Rose and Podolsky Law Offices.http://www.sskrplaw.com/gene/ robertson/complaint.html/ (accessed 03/09/2012).

[61] Weiss v Solomon. A.Q.no 312.1989.http://www.commonlaw.uottawa.ca/index.php? option=com_docmans\&task=doc_download\&gid=1644/ (accessed 03/09/2012)

[62] Zlotnik Shaul R.Reviewing the reviewers: the vague accountability of research ethics committees. Crit. Care; 2002; 6 (2):12-22.

[63] National Commission for the Protection of Human Subjects of Biomedical and Behavioural Research subjects(NCPHSBBRS). Protection of Human Subjects: Institutional Review Boards. Fed Regist; 1978; 43:231-561. 
